CLINICAL STUDY

\title{
Monocarboxylate transporter 8 deficiency: altered thyroid morphology and persistent high triiodothyronine/thyroxine ratio after thyroidectomy
}

\author{
Eva K Wirth, Sien-Yi Sheu ${ }^{1}$, Jazmin Chiu-Ugalde, Remy Sapin², Marc O Klein ${ }^{3}$, Ilona Mossbrugger ${ }^{4}$, \\ Leticia Quintanilla-Martinez $^{4,5}$, Martin Hrabě de Angelis ${ }^{6,7}$, Heiko Krude ${ }^{8}$, Thomas Riebel ${ }^{9}$, Karin Rothe ${ }^{10}$, \\ Josef Köhrle, Kurt W Schmid ${ }^{1}$, Ulrich Schweizer and Annette Grüters ${ }^{8}$ \\ Institut für Experimentelle Endokrinologie, Charité-Universitätsmedizin Berlin, Augustenburger Platz 1, 13353 Berlin, Germany, ${ }^{1}$ Institut für Pathologie \\ und Neuropathologie, Universität Duisburg-Essen, Essen, Germany, ${ }^{2}$ FRE 3289, Centre National de la Recherche Scientifique, Université de Strasbourg, \\ Strasbourg, France, ${ }^{3}$ Service D'Endocrinologie, Centre Hospitalier et Universitaire de Nancy, Nancy, France, ${ }^{4}$ Institute of Pathology, Helmholtz Zentrum \\ München, Munich, Germany, ${ }^{5}$ Institut für Pathologie, Eberhard Karls Universität Tübingen, Tubingen, Germany, ${ }^{6}$ Institute of Experimental Genetics, \\ German Mouse Clinic, Helmholtz Zentrum München, Munich, Germany, ${ }^{7}$ Chair of Experimental Genetics, TUM, Freising/Weihenstephan, Germany, \\ ${ }^{8}$ Institut für Experimentelle Pädiatrische Endokrinologie, Charité-Universitätsmedizin Berlin, Berlin, Germany, ${ }^{9}$ Klinik für Strahlenheilkunde, Pädiatrische \\ Radiologie, Charité-Universitätsmedizin Berlin, Berlin, Germany and ${ }^{10}$ Klinik für Kinderchirurgie, Charité-Universitätsmedizin Berlin, Berlin, Germany \\ (Correspondence should be addressed to U Schweizer; Email: ulrich.schweizer@charite.de)
}

\begin{abstract}
Context: Thyroid hormone transport across the plasma membrane depends on transmembrane transport proteins, including monocarboxylate transporter 8 (MCT8). Mutations in MCT8 (or SLC16A2) lead to a severe form of X-linked psychomotor retardation, which is characterised by elevated plasma triiodothyronine $\left(\mathrm{T}_{3}\right)$ and low/normal thyroxine $\left(\mathrm{T}_{4}\right)$. MCT8 contributes to hormone release from the thyroid gland.

Objective: To characterise the potential impact of MCT8-deficiency on thyroid morphology in a patient and in Mct8-deficient mice.

Design: Thyroid morphology in a patient carrying the A224V mutation was followed by ultrasound imaging for over 10 years. After thyroidectomy, a histopathological analysis was carried out. The findings were compared with histological analyses of mouse thyroids from the Mct $8^{-/ y}$ model.

Results: We show that an inactivating mutation in MCT8 leads to a unique, progressive thyroid follicular pathology in a patient. After thyroidectomy, histological analysis revealed gross morphological changes, including several hyperplastic nodules, microfollicular areas with stromal fibrosis and a small focus of microfollicular structures with nuclear features reminiscent of papillary thyroid carcinoma (PTC). These findings are supported by an Mct8-null mouse model in which we found massive papillary hyperplasia in 6- to 12-month-old mice and nuclear features consistent with PTC in almost 2-year-old animals. After complete thyroidectomy and substitution with levothyroxine $\left(\mathrm{L}-\mathrm{T}_{4}\right)$, the preoperative, inadequately low $\mathrm{T}_{4}$ and free $\mathrm{T}_{4}$ remained, while increasing the $\mathrm{L}-\mathrm{T}_{4}$ dosage led to $\mathrm{T}_{3}$ serum concentrations above the normal range.

Conclusions: Our results implicate peripheral deiodination in the peculiar hormonal constellation of MCT8-deficient patients. Other MCT8-deficient patients should be closely monitored for potential thyroid abnormalities.
\end{abstract}

European Journal of Endocrinology 165 555-561

\section{Introduction}

Mutations in the monocarboxylate transporter 8 (MCT8) gene (SLC16A2) lead to a syndrome of severe psychomotor retardation (1-3), and are the cause for the Allan-Herndon-Dudley syndrome (OMIM 300523), one of the first X-linked mental retardation syndromes described. Patients present with axial hypotonia, spastic or dystonic quadriplegia, and usually do not attain the ability to speak, sit, stand or walk.
Mutations in MCT8 have been described in more than 25 families, including missense, nonsense, splice site and insertion mutations, as well as small and large deletions (1-4). Thus, it is generally assumed that the syndrome is caused by a loss-of-function mechanism. Thyroid hormones need transmembrane transport proteins to cross cellular membranes (5). A number of thyroid hormone transport proteins have been identified, including MCT8, a 12-transmembrane spanning member of the major facilitator superfamily $(6,7)$. 
Several lines of evidence suggest that triiodothyronine $\left(\mathrm{T}_{3}\right)$ transport is impaired in MCT8-deficient patients and in Mct8-deficient mouse models (8-10). While $\mathrm{T}_{3}$ transport is significantly decreased in cortical neurons cultured from Mct8-deficient mice (11), Mct8-deficiency may be partially compensated in some mouse tissues by the coexpression of alternative $\mathrm{T}_{3}$ transporters (11). Recently, two reports showed the involvement of Mct8 in the secretion of thyroid hormones from the thyroid gland in mice $(12,13)$. However, the paradoxically low total thyroxine $\left(\mathrm{T}_{4}\right)$ level in the presence of elevated $\mathrm{T}_{3}$ and normal to high TSH observed both in humans and mice still remains unexplained.

In one patient reported previously (1), thyroid sonography was inconspicuous at 16 months and 3 years of age. From 9 years of age, we have noted progressive hyperperfused nodular changes, which after more than 1 year of further observation became suggestive of thyroid malignancy. Total thyroidectomy was performed in the patient. Histological analysis demonstrated gross morphological alterations in the thyroid, but did not clearly support diagnosis as papillary carcinoma. We also observed a high frequency of papillary thyroid hyperplasia in the Mct8-deficient mouse model. In the oldest mice, these changes were classified as papillary thyroid carcinoma (PTC).

\section{Materials and methods}

\section{The patient}

The detailed endocrine and neurological phenotype of the patient carrying the A224V mutation in MCT8 has been reported previously $(1,14)$. He demonstrates the typical hormonal features of MCT8-deficiency with low serum $\mathrm{T}_{4}$ and elevated $\mathrm{T}_{3}$ levels. As we could show earlier, the A224V mutation enables MCT8 to be still localised at the cell surface, but the mutant protein does not exhibit transport activity in cellular $\mathrm{T}_{3}$-uptake assays (15). In the follow-up protocol of this patient with a so far unknown molecular mechanism in a new rare disease (Doppler)-sonography was included starting from the age of 1 year. Owing to increasing hyperperfusion of nodular changes in the thyroid resulting in a picture resembling thyroid malignancy, thyroidectomy had to be performed at an age of 10 years without complications. Postoperative substitution was initiated with $75 \mu \mathrm{g}$ levothyroxine (L-T $\left.\mathrm{T}_{4}\right)$ per day.

\section{Mice}

The mouse strain carrying a null mutation in the Mct8 gene was described previously $(9,11)$. The mice were of a $\mathrm{C} 57 \mathrm{Bl} / 6 \mathrm{~J}$ genetic background for more than ten backcrosses. Animal experimentation was approved by Landesamt für Gesundheit und Soziales, Berlin, \#T0458/09. A subset of animals had been subjected to the pathology screen at the German Mouse Clinic (Helmholtz Zentrum München) with similar results concerning thyroid pathology as assessed by the laboratory in Essen.

\section{Hormone measurements}

Thyroid hormones from 20 male mice of each genotype $\left(\mathrm{Mct}^{+/ y}\right.$ and $\mathrm{Mct}^{-/ y}$ ) were measured by a competitive RIA (Diasorin, Saluggia, Italy) as described previously (16). TSH in mouse serum was determined by a self-made RIA using a guinea pig anti-mouse TSH antibody (AFP98991) and a crude TSH/LH RP (AFP51718MP) obtained from the National Hormone and Peptide Program (NHPP), USA as described in Streckfuss et al. (16).

\section{QPCR analysis}

Human A pool of total RNA prepared from normal human thyroid tissue was purchased from BioCat (Heidelberg, Germany), reverse transcribed and analysed by qPCR as described recently (11).

Mouse Single thyroids from mice were prepared using a commercial RNA extraction kit, reverse transcribed and analysed by qPCR with an iCycler instrument and SYBR green as described (11). All analyses were done in triplicate. $18 \mathrm{~S}$ rRNA was used as reference gene.

\section{Western blot}

Single thyroids from wild-type $\mathrm{C} 57 \mathrm{Bl} / 6$ and $\mathrm{Mct}^{-/ y}$ were homogenised, separated by SDS-PAGE and transferred to nitrocellulose membrane. The antiMCT8 antibody from Atlas Antibodies (Stockholm, Sweden) was used for detection as described (11). Transferrin served as membrane fraction control.

\section{Histological analyses}

Thyroids were embedded in paraffin and stained with hematoxylin and eosin (H\&E). Immunohistochemical stainings were performed as described (11) with antibodies against Mct8 (1:250, Atlas Antibodies), thyroglobulin (Tg; 1:750, Thermo Fisher Scientific, Waltham, MD, USA) and sodium/iodide symporter (NIS; 1:1200, Acris Antibodies, Herford, Germany). Morphometrical analyses were performed on about 100 follicles per group at the age of 9 months. Axiovision Software (Carl Zeiss AG, Oberkochen, Germany) was used for measurements on a Zeiss Axioscope II mot plus equipped with an AxioCam. The formulas given in the publication of Friedrichs et al. (17) were used.

\section{Deiodinase assay}

Type I deiodinase assay was performed on whole thyroid homogenates as described before (18). 


\section{Ethics statement}

Thyroidectomy was performed, as therapy, not as a research objective, after seeing the progressive changes in the thyroid. Sonography images were presented to a clinical grand round without mentioning the genetic disease of the patient. Because of the feeble condition of the mentally retarded patient, it was decided not to perform multiple fine-needle biopsies. Because surgery was indicated based on the clinical management of the patient and was not part of a scientific study, ethics approval was not obtained. The patient's parents provided written consent for thyroidectomy and publication. There are not yet clinical guidelines for the management of this rare disease.

\section{Results}

\section{Case report}

MCT8 is the most abundant thyroid hormone transporter in the human thyroid as judged by qPCR (Fig. 1A). As in the mouse, MCT8 is located in the basolateral membrane (Fig. 1B). A patient carrying an A224V mutation was described in detail in the initial and a subsequent publication of MCT8-deficiency $(1,14)$, and was followed since the age of 4 months.

Ultrasound features At an age of 16 months, a normal thyroid structure with a small volume $(1.1 \mathrm{ml})$ was found (Fig. 1C). During follow-up, thyroid structures changed gradually with irregular, in part nodular appearance in ultrasound (Fig. 1D), which culminated in a massive hyperperfused, entirely altered thyroid image at an age of 9 years (Fig. 1E and F). During this process of transformation the volume of the thyroid remained within the normal, age-adjusted range. Based on the severe hyperperfusion and the progressive transformation, the suspicion of malignancy arose. We decided to perform complete thyroidectomy when the patient was 10 years old. Since the preoperative calcitonin level was only $5 \mathrm{pg} / \mathrm{ml}$, C-cell hyperplasia or medullary thyroid carcinoma was deemed unlikely.

Pathology Histological analysis revealed microfollicular areas with a peculiar fibrous stroma as well as several nodules with macrofollicular structure (Fig. 1G-I). The stroma was rich in extracellular matrix that was considered responsible for the coarse appearance noted already during surgery (Fig. 1J). Thyroid stroma fibrosis represents a typical feature of various thyroid cancers (papillary and medullary carcinoma); however, a normal distribution of C-cells (not shown) within the areas showing stromal fibrosis argues against malignancy. In a focus of $<5 \mathrm{~mm}$, irregularly shaped nuclei of varying size were noted resembling PTC. However, these nuclear changes were not considered sufficient to justify the diagnosis of PTC (Fig. 1K and L).
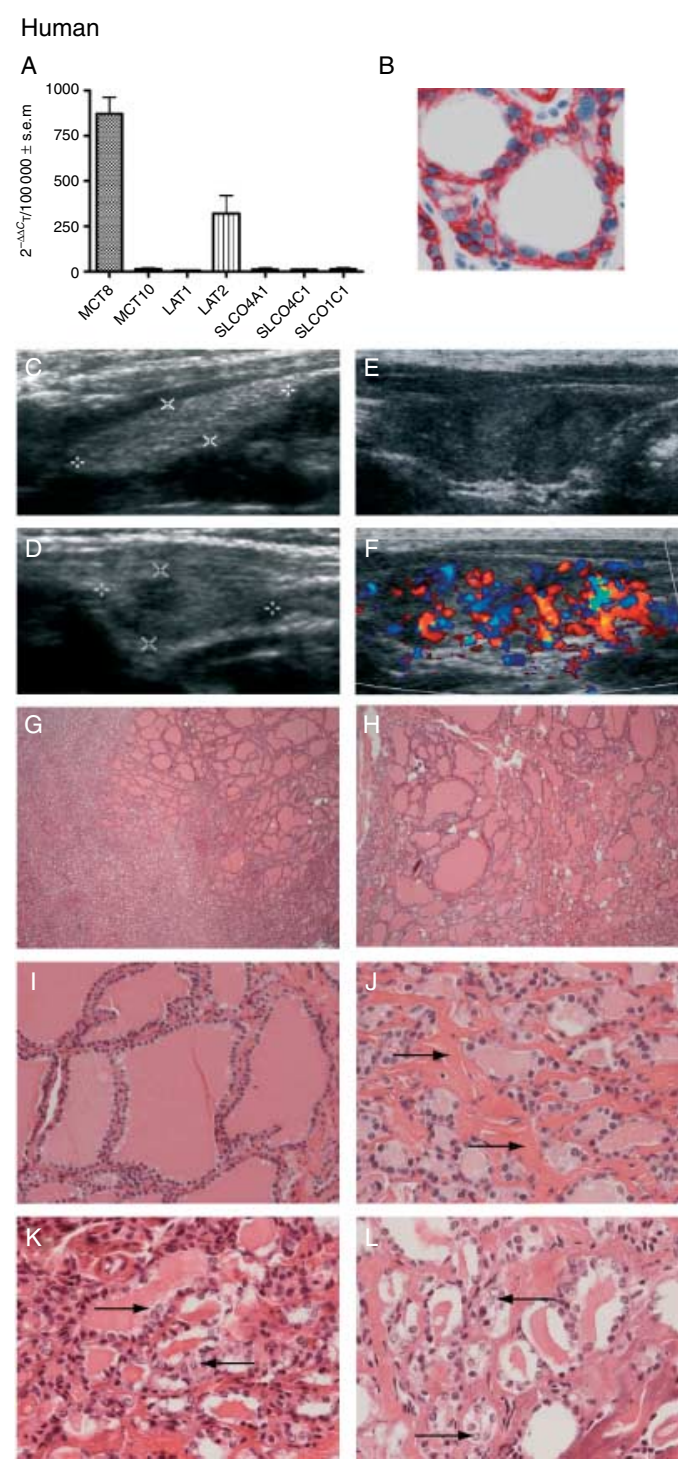

Figure 1 Clinical and pathological features of MCT8-deficiency in a patients thyroid. Expression of MCT8 in the human thyroid. (A) QPCR analyses in the human thyroid gland relative to $\beta$-actin mRNA. MCT8 is the most abundantly expressed $T_{3}$ transporter. Eight transporters were tested. SLC10A1, which is only expressed in liver served as a negative control. (B) Immunohistochemistry for MCT8 in the normal human thyroid. The protein is located in the basolateral membranes of thyrocytes. Ultrasonographic imaging: (C) patient's thyroid at an age of 16 months. (D) Single nodule in the patient's thyroid at the age of 3 years. (E) Still normal-sized thyroid with marked diffuse nodular changes at the age of 9 years with normal volume. (F) Doppler image from $(E)$ shows hyperperfusion. Histological sections of the patient's thyroid: (G) overview. Macrofollicular nodules with epithelial hyperplasia adjacent to a large microfollicular area with stromal fibrosis. (H) Detail from (G), stromal fibrosis surrounding small 'inactive' follicles. (I) Large, active follicles with epithelial invaginations into the colloid. (J) Microfollicular area with stromal sclerosis. (K) Small focus with irregularly shaped nuclei resembling nuclear changes of PTC. (L) Higher magnification of nuclear irregularities: note the pronounced ground-glass appearance of nuclei, whereas another hallmark of PTC, namely the irregular shape of nuclei, is lacking. 


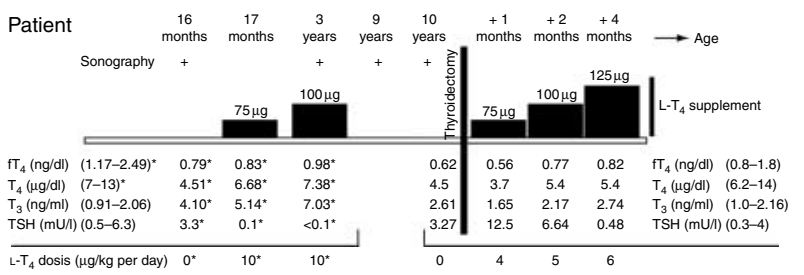

Figure 2 Thyroid function tests in a patient carrying the A224V mutation. Thyroid function tests in a patient carrying the A224V mutation. Patient age is indicated in the top line and sonography is indicated below. L-T 4 supplementation dose is depicted as black columns. Hormone levels and cognate reference values are given below. Data from the same patient already reported in (14) are marked with an asterisk $\left({ }^{*}\right)$. Thyroidectomy is indicated by the vertical bar.

Molecular analysis Additional molecular pathological investigations for BRAF mutations and possible RET/PTC rearrangements from this area yielded negative results (data not shown). Owing to the final diagnosis of a small area of PTC-like histology without clear detection of malignant structures, no further radioiodine therapy was initiated.

Outcome After surgery, the patient was treated with an increasing dose of $\mathrm{L}-\mathrm{T}_{4}$ with the aim to normalise TSH. Treatment was initiated with $75 \mu \mathrm{g} \mathrm{L}-\mathrm{T}_{4}(4 \mu \mathrm{g} / \mathrm{kg}$ per day) and the dose was finally escalated to reach $125 \mu \mathrm{g}$ $(6 \mu \mathrm{g} / \mathrm{kg}$ per day; Fig. 2), a dose normally considered quite high. Accordingly, while $\mathrm{T}_{4}$ and $\mathrm{TSH}$ were normalised, the treatment leads to $\mathrm{T}_{3}$ levels above normal, resembling the same preoperative increased $\mathrm{T}_{3} / \mathrm{T}_{4}$ ratio typical for MCT8-deficient patients. The contribution of residual thyroid tissue to this constellation was excluded by measuring postoperative $\mathrm{Tg}$, which was very low $(0.3 \mu \mathrm{g} / \mathrm{l})$ consistent with complete thyroidectomy.

\section{Mouse modeI}

In parallel to our observations of gradual changes in the patient's thyroid, we took advantage of our Mct8deficient mouse model to investigate whether the observed histological changes are specific for the A224V mutation in the patient or whether lack of functional MCT8 expression in the thyroid bears wider relevance. Mct8 is also the predominant thyroid hormone transporter in the murine thyroid (Fig. 3A), where it shows the same basolateral membrane localisation as in human thyrocytes (Fig. 3B). When we investigated the thyroid tissue from 6-month-old Mct8-deficient mice, we found giant nodules with thyroid follicular cell hyperplasia (Fig. 3C). More detailed examinations of these follicles in $\mathrm{Mct}^{-/ y}$ mice by immunohistochemistry demonstrated normal staining for $\mathrm{Tg}$ and the NIS. Measurements of crosssectional follicular areas indicated a shift towards bigger follicles in $\mathrm{Mct}^{-/ \mathrm{y}}$ mice (Fig. 3D). Follicular epithelial extension was also significantly increased in
A

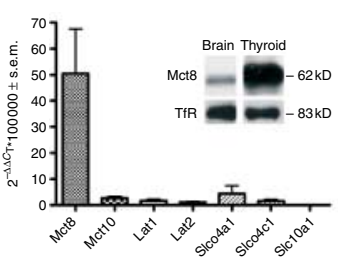

D

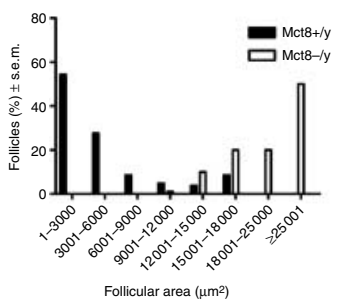

B

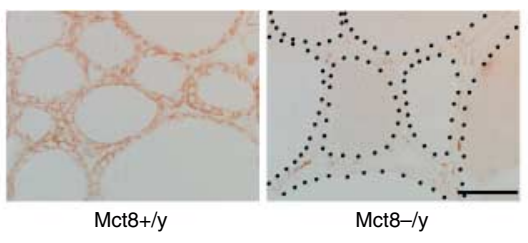

$\mathrm{E}$

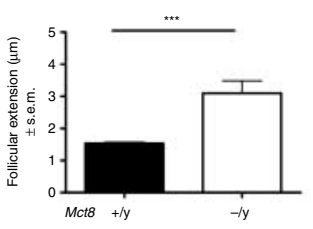

$\mathrm{F}$

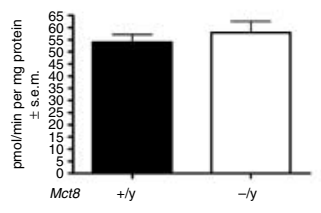

C

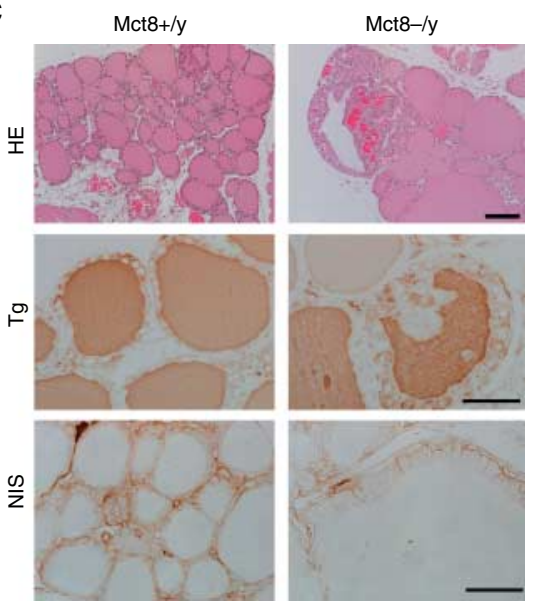

Figure 3 Histological and morphometric alterations in thyroids from Mct8-deficient mice. (A) QPCR analyses in the murine thyroid gland. Mct8 is the most abundantly expressed $\mathrm{T}_{3}$ transporter. Seven out of 14 transporters tested are shown. Liver-specific S/c10a1 was used as a negative control. Inset: Mct8 protein expression in thyroid compared with brain. Transferrin receptor (TfR) served as membrane protein control. (B) Immunohistochemistry for Mct8 in the murine thyroid. The protein is located in the basolateral membrane of thyrocytes. Thyroid tissue from an $M c t 8^{-1 y}$ mouse (right) served as negative control. Follicles are indicated by broken lines. Scale bar $50 \mu \mathrm{m}$. (C) Follicular cell tumour with papillary structures and nuclear features of papillary carcinoma (nuclear infoldings, grooves and other irregularities, elongation and overlapping) in Mct8-deficient thyroids as analysed by H\&E staining, immunohistochemistry for thyroglobulin (Tg) and sodium/iodide symporter (NIS). Note the basolateral localisation of NIS in the aberrant epithelium. Scale bars $50 \mu \mathrm{m}$. (D) Follicular size is increased in Mct8-deficient thyroids. Cross-sectional follicular areas were measured, grouped according to size and the fraction of follicles falling into each group was plotted against the area. (E) Follicular epithelial extension is significantly increased in Mct8-deficient thyroids. ${ }^{* \star *} P<0.001$, Student's $t$-test, two-sided, unpaired. (F) Activity of type I deiodinase is unaltered in Mct8-deficient thyroids. $n=6$ animals/group. 

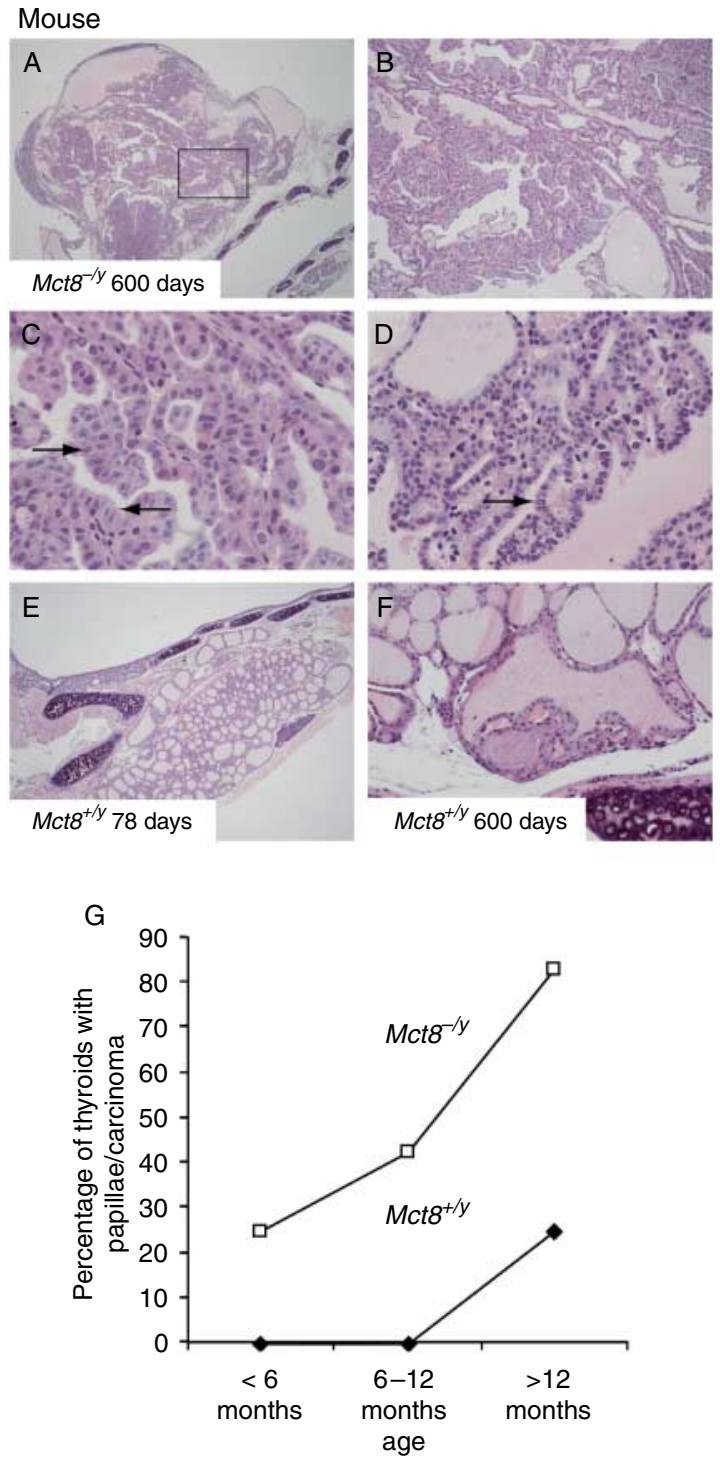

Figure 4 Progressive thyroid pathology in aged Mct8-deficient mice. (A) Thyroid section of a 600 days old $M c t 8^{-1 y}$ mouse. (B) Detail from (A) demonstrates papillary structures. (C and D) Characteristic nuclear features of papillary thyroid carcinoma including irregular shape, nuclear overlap, nuclear pseudoinclusions, crowding and enlargement. (E) Thyroid gland from a 78 days old $M c t 8^{+/ y}$ mouse with normal morphology. (F) Tiny papillary microcarcinoma in the thyroid gland from a 600 days old Mct8 ${ }^{+/ y}$ mouse. $(G)$ Progressive thyroid pathology in Mct8-deficient mice. The fraction in (\%) of thyroids containing papillary lesions is increasing with age. Fifty-six mice were investigated (30 Mct8 ${ }^{-1 y}$ and $26 \mathrm{Mct}^{+/ y}$ mice). Small papillary infoldings occurred in (1/4) $M c t 8^{-1 y}$ and (0/4) Mct8 $8^{+/ y}$ mice younger than 6 months. Papillary lesions occurred in (6/14) Mct8 ${ }^{-1 y}$ and $(0 / 14) M c t 8^{+/ y}$ mice of 6 months to 1 year of age. Papillary lesions and papillary carcinoma of $1-4 \mathrm{~mm}$ size were found in $(11 / 12)$ Mct8 $^{-1 y}$ mice above the age of 2 years. Only two $M c t 8^{+/ y}$ mice out of eight of the same age group harboured very small papillary foci. Fisher's exact test (two-sided) reported significant differences between genotypes at 6 months to 1 year $(P=0.0159)$ and $>1$ year $(P=0.0194)$.
Mct8-deficient mice (Fig. 3E). Diol activity was not different between Mct $8^{-/ y}$ and Mct ${ }^{+/ y}$ thyroids (Fig. 3F). We then analysed the thyroids of mice up to 600 days of age and found even more dramatic changes. In some 600 day-old animals, almost the entire gland consisted of papillary structures (Fig. 4A). Focally, irregular follicular structures showed intraluminal papillary projections with cells exhibiting marked nuclear changes. Based on these nuclear changes, these foci were classified as PTC (Fig. 4B-D). Despite these profound morphological changes, we never observed invasion of adjacent tissues. Thyroids from wild-type mice of this strain remained inconspicuous (Fig. 4E), although occasionally in 600 days old animals, minute papillary structures, similar to those seen in young Mct $8^{-/ y}$ mice, were detected, but these lacked any nuclear changes (Fig. 4F). Large hyperplastic areas were never observed in control animals. Plotting the incidence of papillary changes in the thyroids of mice against animal age revealed an increase of thyroid pathology with time in $M c t 8^{-/ y}$ mice (Fig. 4G). In the group older than 1 year more than $80 \%$ of the mutant mice sustained papillary thyroid alterations.

The only known functions of MCT8 are cellular uptake or release of thyroid hormones. Whereas elevated total serum $\mathrm{T}_{3}$ levels in the face of low normal $\mathrm{T}_{4}$ are found in both human patients and in the Mct8deficient mouse model, some controversy remained whether TSH levels are normal or slightly elevated. We have analysed groups of 20 male mice of each Mct $^{+/ y}$ and Mct $^{-/ y}$ genotype between the age of 3 and 21 months and measured total $\mathrm{T}_{3}, \mathrm{~T}_{4}$ and TSH. Since no variation with age was noted, we pooled the data and finally were able to support a significant twofold increase in TSH in the Mct8-deficient group (Fig. 5).

\section{Discussion}

We describe here, for the first time, a case of altered thyroid morphology in a patient with MCT8-deficiency. Progressive changes in thyroid morphology were followed over the years and resulted in total thyroidectomy. Histological analysis demonstrated massive morphological alterations, but did not clearly support diagnosis of PTC. In fact, the appearance of the patient's thyroid does not completely resemble any syndrome we are aware of. Papillary thyroid hyperplasia develops with age in Mct8-deficient mice supporting the notion that changes in thyroid histology are related to the lossof-function genotype of MCT8 in the patient. Nuclear changes in very old Mct8-deficient mice are consistent with PTC. A problem for comparison is that the histological pictures are not exactly the same in the patient and mouse model. Apart from the species differences that are also seen in other aspects of this syndrome, the loss-of-function mutation in MCT8/Mct8 occurs in both instances. It is unclear at present what 


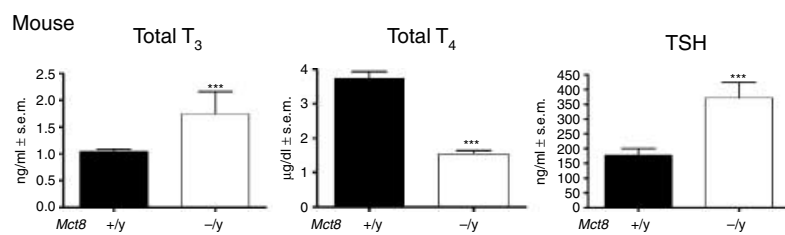

Figure 5 Thyroid function tests in Mct8-deficient mice. Total $\mathrm{T}_{3}$ is increased, while total $\mathrm{T}_{4}$ is inappropriately low in $M c t 8^{-1 y}$ mice. TSH is significantly increased in the mutants. Animals were 3-21 months of age. No correlation of $T_{3}$ and $T_{4}$ values with age was noted. TSH increased with age. ${ }^{\star \star \star} P<0.001$, Mann-Whitney $U$ test.

kind of mechanism could underlie the progressive thyroid changes upon loss of MCT8 function. One possibility could be a cell-autonomous defect of thyroid hormone release with a possible exposure to increased thyroid hormone signaling within the thyrocyte. Alternatively, Mct8 may be involved in the export from thyrocytes of toxic metabolites, although there is as present no indication of any Mct8 substrate other than iodothyronines. Several genetic alterations are observed in thyroid cancer and have guided the generation of respective mouse models (19). These include germline or somatic mutations in BRAF (20) and RET (21). RET/PTC3-transgenic mice develop PTC with lymph node metastases (21). A careful and detailed histological comparison of RET/PTC3- and human papillomavirus type 16 E7-transgenic ( $\mathrm{Tg}$-E7) mice showed that RET/PTC3 mice appear as a partial and transient model of human PTCs, while human papillomavirus type $16 \mathrm{E} 7$-transgenic mice present with a dominant goitrous pattern of thyroid changes (22). In younger $\mathrm{Mct}^{-/ \mathrm{y}}$ mice, the follicular pattern comprising a mixture of huge follicles lined with flat epithelia and irregularly shaped follicles with 'palissade-like' folded epithelia resembles $\mathrm{Tg}$-E7 mice. Mct8 ${ }^{-1 y}$ and Tg-E7 thyroids thus bear some similarity to goiter. Papillary thyroid cancer in $B R A F^{\mathrm{V} 600 \mathrm{E}}$-transgenic mice is growing rapidly and invades adjacent tissue (20). Thyroid growth in Mct8-deficient mice is much slower than in RET/PTC3- and BRAF ${ }^{\mathrm{V} 600 \mathrm{E}}$-transgenic mice. Moreover, we observed neither lymph node or distant metastases nor invasive growth into perithyroidal structures. Pathological changes in Mct8-deficient mice are therefore different from any described mouse model of thyroid carcinomas. We speculate that constant TSH stimulation may contribute to elevated follicular activity and proliferation as in iodine-deficient goiter, Graves' disease (23), and mutations in the thyroid hormone biosynthetic pathway (24). This notion is supported by the observations by us and others of increased follicular epithelial extension (12). Similar as in a case of long-standing goiter due to Pendred's syndrome, elevated TSH levels may predispose to hyperplasia that may result in eventual neoplasia upon the accumulation of additional somatic mutations (25). Senou et al. (26) have recently demonstrated oxidative stress in Pendred's thyrocytes that may lead to genomic damage. We have observed a robust twofold elevation of plasma TSH in Mct8deficient mice that, if sustained over years, may promote the growth of papillary carcinomas, which might otherwise have remained undetected tiny lesions. At the moment, it is not possible in our model to clearly separate the influence of chronically elevated TSH from a cell-autonomous loss- or gain-of-function phenotype of Mct8-inactivation. Any manipulation of thyroid function to the effect of elevated TSH may result in other confounding metabolic alterations. Notably, increased TSH is not a consistent finding in patients with MCT8-deficiency, nor have TSH levels been significantly elevated in the patient described in this study. Therefore, additional mechanisms need to be considered to explain the complete structural transformation of the patient's thyroid tissue.

Another unresolved question is the mechanism underlying the inappropriately low $\mathrm{T}_{4}$ found in patients and in the mouse model. We suggest that our findings in the thyroidectomised patient could help resolve this issue: since Mct8 is apparently involved in thyroidal hormone secretion (12), it was proposed that unbalanced release of thyroid hormones may underlie the low $\mathrm{T}_{4}$ levels in the MCT8-deficiency syndrome (13). However, increased instead of decreased $\mathrm{T}_{3}$ is a robust finding in patients and mice lacking MCT8. In addition, impaired thyroidal release of iodothyronines from an MCT8-deficient gland is unlikely the primary cause of the peculiar high $\mathrm{T}_{3}$, low $\mathrm{T}_{4}$ and high-normal TSH profile, since this pattern persisted after thyroidectomy and $\mathrm{L}_{-} \mathrm{T}_{4}$ substitution therapy. In our eyes, MCT8deficiency may cause a relative pituitary insensitivity towards $\mathrm{T}_{3}$ and peripheral deiodination may lead to diminished $\mathrm{T}_{4}$ levels. This interpretation is consistent with the observation that $\mathrm{T}_{4}$ supplementation of athyroid $\mathrm{Pax} 8^{-/-}$; $\mathrm{Mct}^{-/ y}$ mice revealed inappropriately low $\mathrm{T}_{4}$ levels compared with $\mathrm{T}_{3}$ (13). This finding in combination with our data from the patient strongly argues for an extrathyroidal, possibly deiodinationdependent, mechanism responsible for the high $\mathrm{T}_{3}$-low $\mathrm{T}_{4}$ constellation in MCT8-deficiency.

In clinical practice, thyroid pathology should be closely monitored in patients with other MCT8 mutations to establish whether the thyroid morphological changes are common to the MCT8-deficiency syndrome.

\section{Declaration of interest}

The authors declare that there is no conflict of interest that could be perceived as prejudicing the impartiality of the research reported.

\section{Funding}

J Chiu-Ugalde was supported by a fellowship of the German Academic Exchange Service DAAD. This work was supported by grants of the Deutsche Forschungsgemeinschaft SFB 665 TP A7 to Schweizer and Grüters, European Union Grant EUMODIC LSHG-2006-037188 
(German Mouse Clinic) and by the German Federal Ministry of Education and Research to the GMC (NGFNplus grant no. 01GS0850) to L Quintanilla-Martinez and M Hrabe de Angelis.

\section{References}

1 Friesema EC, Grueters A, Biebermann H, Krude H, von Moers A, Reeser M, Barrett TG, Mancilla EE, Svensson J, Kester MH, Kuiper GG, Balkassmi S, Uitterlinden AG, Koehrle J, Rodien P, Halestrap AP \& Visser TJ. Association between mutations in a thyroid hormone transporter and severe X-linked psychomotor retardation. Lancet $2004 \mathbf{3 6 4} 1435-1437$. (doi:10.1016/S01406736(04)17226-7)

2 Dumitrescu AM, Liao XH, Best TB, Brockmann K \& Refetoff S. A novel syndrome combining thyroid and neurological abnormalities is associated with mutations in a monocarboxylate transporter gene. American Journal of Human Genetics $2004 \mathbf{7 4}$ 168-175. (doi:10.1086/380999)

3 Schwartz CE, May MM, Carpenter NJ, Rogers RC, Martin J. Bialer MG, Ward J, Sanabria J, Marsa S, Lewis JA, Echeverri R, Lubs HA, Voeller K, Simensen RJ \& Stevenson RE. Allan-HerndonDudley syndrome and the monocarboxylate transporter 8 (MCT8) gene. American Journal of Human Genetics 200577 41-53. (doi:10. 1086/431313)

4 Friesema EC, Visser WE \& Visser TJ. Genetics and phenomics of thyroid hormone transport by MCT8. Molecular and Cellular Endocrinology 2010222 107-113. (doi:10.1016/j.mce.2010.01. 016)

5 Hennemann G, Docter R, Friesema EC, de Jong M, Krenning EP \& Visser TJ. Plasma membrane transport of thyroid hormones and its role in thyroid hormone metabolism and bioavailability. Endocrine Reviews 200122 451-476. (doi:10.1210/er.22.4.451)

6 Friesema EC, Ganguly S, Abdalla A, Manning Fox JE, Halestrap AP \& Visser TJ. Identification of monocarboxylate transporter 8 as a specific thyroid hormone transporter. Journal of Biological Chemistry 2003278 40128-40135. (doi:10.1074/jbc.M300909200)

7 Kinne A, Kleinau G, Hoefig CS, Grüters A, Köhrle J, Krause G \& Schweizer U. Essential molecular determinants for thyroid hormone transport and first structural implications for monocarboxylate transporter 8. Journal of Biological Chemistry 2010 285 28054-28063. (doi:10.1074/jbc.M110.129577)

8 Dumitrescu AM, Liao XH, Weiss RE, Millen K \& Refetoff S. Tissuespecific thyroid hormone deprivation and excess in monocarboxylate transporter (mct) 8-deficient mice. Endocrinology $2006 \mathbf{1 4 7}$ 4036-4043. (doi:10.1210/en.2006-0390)

9 Trajkovic M, Visser TJ, Mittag J. Horn S, Lukas J, Darras VM, Raivich G, Bauer K \& Heuer H. Abnormal thyroid hormone metabolism in mice lacking the monocarboxylate transporter 8 . Journal of Clinical Investigation 2007117 627-635. (doi:10.1172/ JCI28253)

10 Ceballos A, Belinchon MM, Sanchez-Mendoza E, GrijotaMartinez C, Dumitrescu AM, Refetoff S, Morte B \& Bernal J. Importance of monocarboxylate transporter 8 for the blood-brain barrier-dependent availability of 3,5,3'-triiodo-L-thyronine. Endocrinology 2009150 2491-2496. (doi:10.1210/en.2008-1616)

11 Wirth EK, Roth S, Blechschmidt C, Holter SM, Becker L, Racz I, Zimmer A, Klopstock T, Gailus-Durner V, Fuchs H, Wurst W, Naumann T, Bräuer A, Hrabě de Angelis M, Köhrle J, Grüters A \& Schweizer U. Neuronal $3^{\prime}, 3,5$-triiodothyronine $\left(\mathrm{T}_{3}\right)$ uptake and behavioral phenotype of mice deficient in Mct8, the neuronal $\mathrm{T}_{3}$ transporter mutated in Allan-Herndon-Dudley syndrome. Journal of Neuroscience 200929 9439-9449. (doi:10.1523/ JNEUROSCI.6055-08.2009)

12 Di Cosmo C, Liao XH, Dumitrescu AM, Philp NJ, Weiss RE \& Refetoff S. Mice deficient in MCT8 reveal a mechanism regulating thyroid hormone secretion. Journal of Clinical Investigation 2010 120 3377-3388. (doi:10.1172/JCI42113)

13 Trajkovic-Arsic M, Muller J, Darras VM, Groba C, Lee S, Weih D, Bauer K, Visser TJ \& Heuer H. Impact of monocarboxylate transporter- 8 deficiency on the hypothalamus-pituitary-thyroid axis in mice. Endocrinology 2010151 5053-5062. (doi:10.1210/ en.2010-0593)

14 Biebermann H, Ambrugger P, Tarnow P, von Moers A, Schweizer U \& Grueters A. Extended clinical phenotype, endocrine investigations and functional studies of a loss-of-function mutation A150V in the thyroid hormone specific transporter MCT8. European Journal of Endocrinology 2005153 359-366. (doi:10. 1530/eje.1.01980)

15 Kinne A, Roth S, Biebermann H, Köhrle J, Grüters A \& Schweizer U. Surface translocation and tri-iodothyronine uptake of mutant MCT8 proteins are cell type-dependent. Journal of Molecular Endocrinology 200943 263-271. (doi:10.1677/JME09-0043)

16 Streckfuss F, Hamann I, Schomburg L, Michaelis M, Sapin R, Klein MO, Köhrle J \& Schweizer U. Hepatic deiodinase activity is dispensable for the maintenance of normal circulating thyroid hormone levels in mice. Biochemical and Biophysical Research Communications 2005337 739-745. (doi:10.1016/j.bbrc.2005. 09.102)

17 Friedrichs B, Tepel C, Reinheckel T, Deussing J, von Figura K, Herzog V, Peters C, Saftig P \& Brix K. Thyroid functions of mouse cathepsins B, K, and L. Journal of Clinical Investigation 2003111 1733-1745. (doi:10.1172/JCI15990)

18 Schomburg L, Riese C, Michaelis M, Griebert E, Klein MO, Sapin R, Schweizer U \& Köhrle J. Synthesis and metabolism of thyroid hormones is preferentially maintained in selenium-deficient transgenic mice. Endocrinology 2006147 1306-1313. (doi:10. 1210/en.2005-1089)

19 Knostman KA, Jhiang SM \& Capen CC. Genetic alterations in thyroid cancer: the role of mouse models. Veterinary Pathology 200744 1-14. (doi:10.1354/vp.44-1-1)

20 Knauf JA, Ma X, Smith EP, Zhang L, Mitsutake N, Liao XH, Refetoff S, Nikiforov YE \& Fagin JA. Targeted expression of $\mathrm{BRAF}^{\mathrm{V} 600 \mathrm{E}}$ in thyroid cells of transgenic mice results in papillary thyroid cancers that undergo dedifferentiation. Cancer Research 200565 4238-4245. (doi:10.1158/0008-5472.CAN-05-0047)

21 Powell DJ Jr, Russell J, Nibu K, Li G, Rhee E, Liao M, Goldstein M, Keane WM, Santoro M, Fusco A \& Rothstein JL. The RET/PTC3 oncogene: metastatic solid-type papillary carcinomas in murine thyroids. Cancer Research $1998 \mathbf{5 8} 5523-5528$.

22 Jin L, Burniat A, Dumont JE, Miot F, Corvilain B \& Franc B. Human thyroid tumours, the puzzling lessons from E7 and RET/PTC3 transgenic mice. British Journal of Cancer 200899 1874-1883. (doi:10.1038/sj.bjc.6604740)

23 Stocker DJ \& Burch HB. Thyroid cancer yield in patients with Graves' disease. Minerva Endocrinologica 200328 205-212.

24 Hishinuma A, Fukata S, Kakudo K, Murata Y \& Ieiri T. High incidence of thyroid cancer in long-standing goiters with thyroglobulin mutations. Thyroid 200515 1079-1084. (doi:10. 1089/thy.2005.15.1079)

25 Camargo R, Limbert E, Gillam M, Henriques MM, Fernandes C, Catarino AL, Soares J, Alves VA, Kopp P \& Medeiros-Neto G. Aggressive metastatic follicular thyroid carcinoma with anaplastic transformation arising from a long-standing goiter in a patient with Pendred's syndrome. Thyroid 200111 981-988. (doi:10. 1089/105072501753211073)

26 Senou M, Khalifa C, Thimmesch M, Jouret F, Devuyst O, Col V, Audinot JN, Lipnik P, Moreno JC, Van Sande J, Dumont JE, Many MC, Colin IM \& Gerard AC. A coherent organization of differentiation proteins is required to maintain an appropriate thyroid function in the Pendred thyroid. Journal of Clinical Endocrinology and Metabolism 201095 4021-4030. (doi:10. 1210/jc.2010-0228)

Received 27 April 2011

Revised version received 28 July 2011

Accepted 3 August 2011 